\title{
TEMPERATURE CONTROL OF THE CHELTENHAM MAGNETIC OBSERVATORY U. S. COAST AND GEODETIC SURVEY. ${ }^{1}$
}

\author{
By J. E. Burbank. ${ }^{2}$
}

A FULL description of the Cheltenham Magnetic Observatory the Coast and Geodetic survey for the year 1902, Appendix No. 5. ${ }^{2}$

The survey had maintained a magnetic observatory at Los Angeles, California, from 1882 to I 889 and also at San Antonio, Texas, during the period 1892 to I 895. In addition to the experience already gained a careful study was made of the best known foreign observatories and the methods employed to control temperature changes in their variation buildings.

As a result of this study it was decided to build the Cheltenham Observatory entirely above ground and provide sufficient heat insulation to reduce the annual range of temperature inside to a reasonably small amount, such a building would furthermore be free from the excessively humid conditions present in an underground structure.

The observatory is essentially a building within a building, the

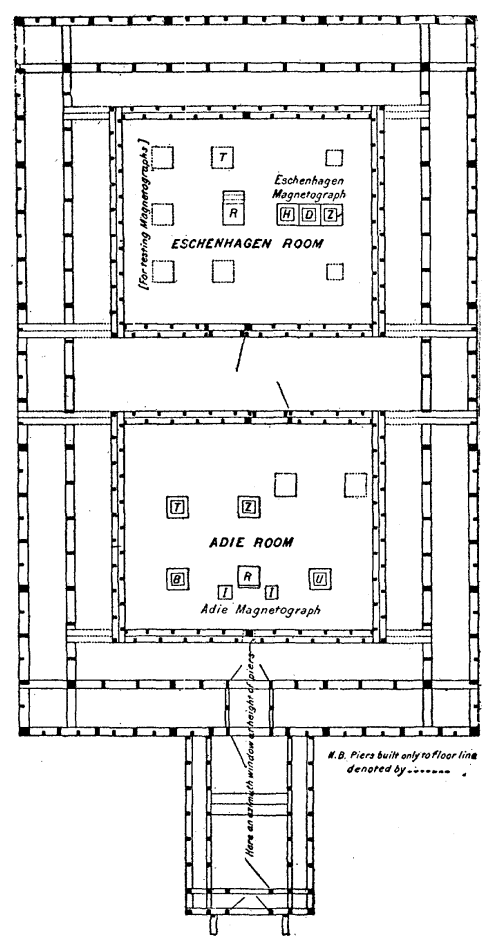

Fig. 1.

${ }^{1}$ Communicated with permission of the Superintendent Coast and Geodetic Survey. 2 Observer in Charge of Cheltenham Magnetic Observatory.

${ }^{3}$ See also Journal Terrestrial Magnetism, March, I903, pp. II-29. 
[VOL. XXV.

inner portion being divided into two separate closed rooms known respectively, as the Adie and Eschenhagen rooms from the types of magnetographs which they contain. The walls of the outer building and also of the inner rooms are packed with dry pine sawdust.

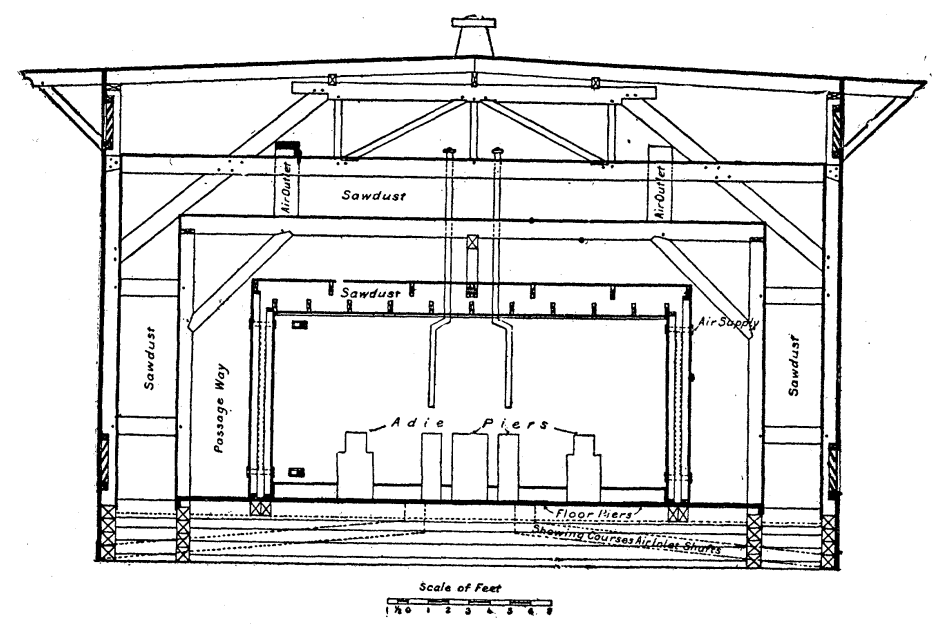

Fig. 2.

The wall thickness was designed to reduce the mean annual range of temperature, about $25^{\circ} \mathrm{C}$. outside, to 4 or $5^{\circ} \mathrm{C}$. inside, assuming no artificial heat and no openings in the walls for entrance or ventilation. For a plan of the variation building see Figs. I and $2 .^{2}$

The inner rooms are each $191 / 2$ by 16 by 9 feet inside measure and are entered through refrigerator pattern doors from a central corridor, $51 / 2$ feet wide, extending between them, the sides and top are surrounded by an air space about 3 feet wide. In each room there are four small air shafts 3 inches square communicating with the air space around the rooms, these are fitted with slides and are generally kept closed. In the Adie room are three 3 -inch ventilating tubes directly over the lamps and extending up into the attic, to carry off the hot air and products of combustion ; during the winter these lamp ventilators are disconnected directly over the top of the room. A similar ventilator is provided in the Eschenhagen room. The doors, air shafts and lamp ventilators are the only openings in the inner rooms. 
In the walls of the outer building there are four inlet shafts 5 by Io inches and 16 feet long so placed that the air enters from the outside of the building near the ground and discharges through floor gratings into the passage-way at either end of the building. Four corresponding air outlet shafts 6 by 10 inches extend through the upper layer of sawdust into the attic. These air shafts are all provided with close fitting shutters and are opened only during the warm summer months. The outside wall has an 8-inch air space between the sawdust packing and the weatherboarding, connecting with the attic space, and provided with six ventilating windows, three on each side of the building near the ground; during the hot weather these air shafts admit a cooling draft around the building during the night hours.

Entrance to the building is from the south side through a vestibule Io feet by I 3 feet 8 inches with walls containing two feet of sawdust packing. This vestibule is divided into three compartments, or air-locks, by four sets of close fitting doors.

The insulation of the building, beginning on the outside is : pine weatherboarding, 8-ply building paper, I-inch pine sheathing, 8inch air shaft, I-inch pine sheathing, 8-ply paper, 3 feet pine sawdust, 8-ply paper, seven eighths inch pine ceiling, 3 feet 2 inches air space of passage-way, seven eighths inch pine ceiling, 8-ply paper, I foot pine sawdust, 8-ply paper, seven eighths inch pine ceiling. Beginning at the roof and going down the insulation is : gravel and pitch roof, three thickness tar paper, I-inch pine sheathing, 3 feet 8 inches air space, $\mathrm{I}$-inch rough pine floor, 3 feet pine sawdust, 8-ply paper, seven eighths inch pine ceiling, 3 feet air space above rooms, I-inch rough pine floor, I foot 6 inches sawdust, 8ply paper, seven eighths inch pine ceiling, seven eighths inch pine floor, 8-ply paper, I-inch pine under floor, 3 feet pine sawdust, 6inch to 8 -inch layer of gravel, 2 feet 8 inches of earth.

During the summer months, from about June I until October I 5 , the attic shutters are kept open so that a comparatively free circulation of air is obtained under the roof. During the night hours and on cool cloudy days the inlet shafts and the lower side shutters are opened allowing circulation of the air in the passageway around the rooms and in the air shafts in the outside walls. 
[VoL. XXV.

The Adie magnetograph consists of three photographic recording variometers each of which is lighted by a central draft student lamp. These lamps run continuously throughout the year, being kept as low as possible during the summer, they consume approximately I $\mathrm{I} / 2$ pints of common kerosene oil per 24 hours.

In the Eschenhagen room only one small lamp is used to light all three variometers. It uses approximately $\mathrm{x} / 2$ pint of oil in 24 hours. The presence of these lamps necessitates a temperature, in summer, considerably higher than the outside mean temperature, and in order to diminish the annual range it is necessary to maintain a correspondingly high temperature in winter. On account of the irregular nature of this source of heat any accurate control is out of the question, and it is not probable that any automatic device could be made to work satisfactorily.

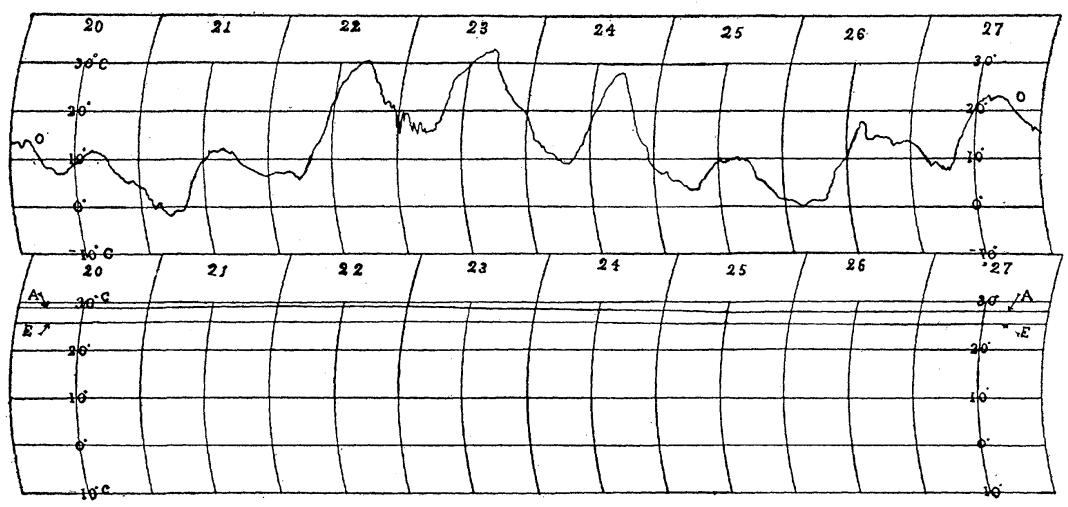

Fig. 3.

Thermograms Cheltenham Magnetic Observatory, March 20-27, 1907, O, Outside, $A$, Adie Room, $E$, Eschenhagen Room.

During the winter months additional lamps similar to the Adie lamps are used to heat the passage-way around the Eschenhagen room, in the coldest weather four or five are used continuously.

As a result of the past four years' record it has been shown that there is no diurnal variation, the occasional changes of one or more tenths of a degree being due to irregularities in the control of the heating lamps or ventilators. These irregularities are most common in the Adie room in the winter when the lamp ventilators are shut 
off, at such times the change may amount to three or four tenths of a degree in a single night, due largely to irregularities in the Adie lamps. The changes in the Eschenhagen room rarely exceed one tenth of a degree in 24 hours.

It has been found that a temperature of about $28^{\circ} \mathrm{C}$. in the Adie, and $25^{\circ} \mathrm{C}$. in the Eschenhagen room, is best suited to present conditions.

It has been found repeatedly that a sudden change, amounting to $20^{\circ} \mathrm{C}$. or $30^{\circ} \mathrm{C}$. outside, can be entirely counteracted by the judicious use of heating lamps in winter and ventilators in summer, and in the case of long continued cold weather the effects are felt only gradually inside and need never amount to more than a few tenths of a degree.

As an example of the effect of a sudden change of temperature outside, see Fig. 3, which is copied from the thermograms obtained in the Adie room $(A)$, in the Eschenhagen room $(E)$, and outside $(O)$, during the period March 20 to March 27, 1907. During this time there was an exceptionally large change of temperature, from $-2^{\circ} \mathrm{C}$. at 5 a. m. March $2 \mathrm{I}$, to $33^{\circ} \mathrm{C}$. at $4 \mathrm{p}$. m. March 23 , a change of $35^{\circ} \mathrm{C}$. in 59 hours. The thermograph pen in the Eschenhagen room, which is normally four tenths of a degree higher than the tnstrument thermometers during this period, due to its setting when ihe sheet was changed, rose from $25.6^{\circ}$ on March 20 , to $25.9^{\circ}$ on March 23, and fell to $25.4^{\circ}$ on March 27. The rise was due largely to extra lamps used during ventilation of the passage-way on March 21. During the period March 24 to 27, when the effect of the hot wave should have been felt, the temperature inside the building was falling on account of the control of the heating lamps. In the Adie room the effect was similar but somewhat larger, there the decrease began on the $22 \mathrm{~d}$. In this particular instance the effect of the hot wave was overestimated and insufficient allowance was made for the low temperature of the sawdust packing.

In addition to a Richard thermograph in each room, each of the magnetic variometers is supplied with a thermometer and all of these thermometers are read daily at $8 \mathrm{a} . \mathrm{m}$. and $4 \mathrm{p}$. m. From these readings, by aid of the thermograms, a table of hourly values is constructed, and from these hourly values the daily and monthly 
[Yol, XXV.

mean values are derived. Since the declination results require no temperature corrections the mean of the temperatures of the two ntensity variometers is taken as the magnetograph temperature.

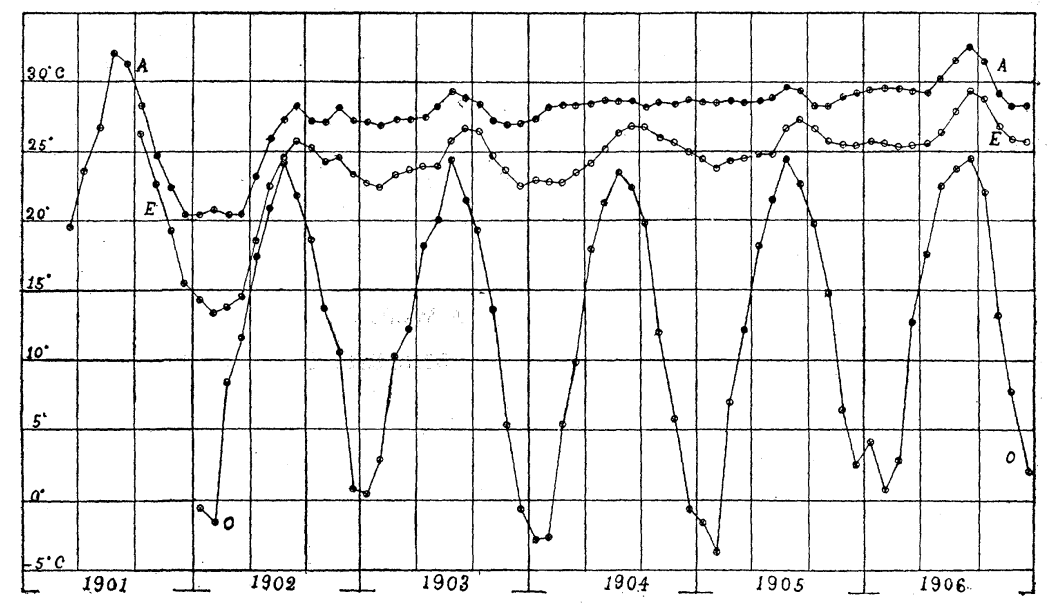

Fig. 4.

Monthly Mean Temperatures Cheltenham, Magnetic Observatory, Igor to Igo6. Adie Room $(A)$, Eschenhagen Room $(E)$, Outside $(O)$.

In Fig. 4 are plotted the monthly mean temperatures, in degrees centigrade; of the Adie magnetograph (curve $A$ ), of the Eschenhagen magnetograph (curve $E$ ), and outside (curve $O$ ), from the beginning of each series of observations to the end of 1906. For the present comparison the monthly mean outside temperatures are derived from the daily maxima and minima. The mean derived in this way will doubtless differ somewhat from the monthly mean value of the hourly readings of the thermograms.

As will be noted the curves for the years I90I and 1902 show that the method of temperature control was in the experimental stage and a comparatively large annual range was obtained. Beginning with 1903 a more careful control was exercised, especially over the Adie room which shows a much smaller annual range than the Eschenhagen. The curves also show a gradual upward tendency during the years 1905 and 1906 , corresponding to the upward tendency of the outside temperature during those years. The lag of the inside temperature change over that outside is also shown in the case of the summer maxima in the Eschenhagen room. 
The temperature ranges in degrees centigrade for the various years are given in the following table:

Annual Temperature Range in Degrees Centigrade.

\begin{tabular}{l|r|r|r|r|r}
\hline & 1902. & I903. & 1904. & I905. & \multicolumn{1}{|c}{ I906. } \\
\hline Adie room. & 7.79 & 2.39 & 1.30 & 1.43 & 4.46 \\
Eschenhagen room. & 12.37 & 4.34 & 4.12 & 3.38 & 4.05 \\
Outside (approximate). & 26.00 & 25.00 & 26.00 & 28.00 & 23.70 \\
\hline
\end{tabular}

Very little is yet known regarding the effect of changes of humidity on the quartz fibers supporting the Eschenhagen magnets, the effect of such changes on the silk fibers supporting the Adie magnets is undesirable. Beginning with 1902 , observations of relative humidity have been made daily by means of a sling psychrometer, outside at 7:50 a. m., in the variation rooms between 8:10 and 8:20 a. $m$. The results show a slow but regular change inside the ob-

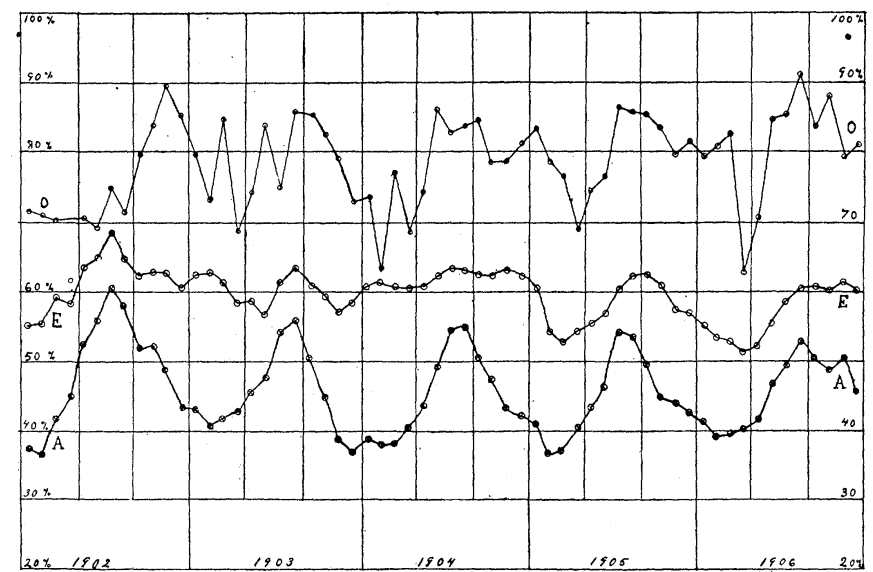

Fig. 5

Monthly Mean Values of Relative Humidity, Cheltenham Magnetic Observatory, 1902 to 1906 . Outside $(O)$, Adie $(A)$, Eschenhagen $(E)$.

servatory with a maximum in summer and a minimum in winter, when the building is kept closed. The monthly range is seldom more than 2 or 3 per cent., while the annual range in the Adie room is about $\mathrm{I} 5$ to $\mathrm{I} 8$ per cent.

In Fig. 5 are plotted the monthly mean values of the relative 
[VOL. XXV.

humidity, in per cent. for the Adie room $(A)$, for the Eschenhagen room $(E)$, and outside $(O)$. The monthly mean of the relative humidity outside has no very great significance beyond showing the greater humidity in summer. It will be noted that the relative humidity in the Adie room is much lower than in the Eschenhagen due probably to the presence of the three lamps and the consequently dryer atmosphere. The higher humidity in summer is caused by the method of ventilating the building during cloudy days and during the night hours.

The total yearly consumption of oil at the observatory is approximately 300 gallons of which about 50 gallons is used in the absolute building, leaving about 250 gallons as the total amount used in heating and lighting the variation building. Of this 250 gallons, about $\mathrm{I} 75$ are used to illuminate the magnetographs, the remainder being used in the heating lamps in winter. This involves a total cost, for heat and light, of about $\$ 25.00$ per year. 